\title{
Justicia y pandemia en España (2020)
}

Justice and pandemic in Spain (2020)

\section{JOSÉ MARTÍN OSTOS}

Catedrático de Derecho Procesal

Universidad de Sevilla (España)

martinos@us.es

https://orcid.org/0000-0002-5489-6004

Resumen: La Administración de Justicia durante el estado de alarma a causa de la crisis sanitaria provocada por Covid-19

Abstract: The administration of justice during the state of alarm declared because of the health crisis caused by the Covid19.

Palabras claves: Administración de Justicia, Tribunales, Fiscalía, Abogacía, estado de alarma, Ministerio de Justicia

Key words: Administration of justice, courts, prosecutor's office, state of alarm, Ministry of Justice.

Sumario: 1. PALABRAS PREVIAS. 2. LA DECLARACIÓN DEL ESTADO DE ALARMA (RD 463/2020). 3. LA PREOCUPACIÓN POR LA JUSTICIA (RD-L 16/2020). 3.1. Capítulo primero. 3.1.A. Días hábiles. 3.1.B. Plazos procesales. 3.1.C. Nuevo procedimiento. 3.1.D. Tramitación preferente de determinados procedimientos (art. 7 del comentado Real Decreto-ley). 3.2. Capítulo segundo. 3.3. Capítulo tercero. 3.3.A. Celebración de actos procesales mediante presencia telemática. 3.3.B. Acceso a las salas de vistas. 3.3.C. Exploraciones médico-forenses. 3.3.D. Uso de toga. 3.3.E. Atención al público. 3.3.F. Órganos judiciales para asuntos de COVID-19. 3.3.G. Jueces de Adscripción 
Territorial. 3.3.H. Asignación de funciones. 3.3.I. Jornada laboral. 3.3.J. Situación y refuerzo de Letrados de la Administración de Justicia. 3.4. Otras disposiciones. 4. LA SITUACIÓN DEL PODER JUDICIAL. 4.1. Paralización general. 4.2. Reanudación escalonada. 4.3. Nuevos órganos judiciales. IV.4. Cursos de especialización y oposiciones a la Carrera Judicial y Fiscal. 5. EL MINISTERIO DE JUSTICIA. 6. LA FISCALÍA GENERAL DEL ESTADO Y LOS PLAZOS DE INSTRUCCIÓN. 7. LOS COLEGIOS DE ABOGADOS. 8. EL ESTADO DE ALARMA ENTRE REJAS. 9. LAS PRÓRROGAS DEL ESTADO DE ALARMA. 9.1. Hasta junio de 2020. 9.2. Por plazo superior. 9.3. Los estados de alarma en el futuro. 10. RECURSOS DE INCONSTITUCIONALIDAD. 11. CONCLUSIONES. 12. ÚLTIMA HORA.

\section{PALABRAS PREVIAS}

A partir de la celebración el día 8 de marzo -en Madrid- de la famosa marcha feminista (no la única, pero sí la más importante, con la asistencia de relevantes autoridades, algunas de las cuales resultaron contagiadas por el peligroso virus) y de las preocupantes noticias llegadas desde el extranjero, comenzaron a adoptarse medidas de prevención de cara a la posible difusión de la enfermedad.

Aprobado el estado de alarma como primera medida de urgencia, se fueron paulatinamente dictando numerosas disposiciones; nos detendremos en las de mayor repercusión en la Administración de Justicia, que es el tema que aquí nos ocupa.

\section{LA DECLARACIÓN DEL ESTADO DE ALARMA (RD 463/2020)}

El 14 de marzo de 2020 (BOE del mismo día) se sancionó el Real Decreto 463/2020 declarando el estado de alarma para la gestión de la situación de crisis sanitaria ocasionada por el COVID$19^{1}$.

Ello se hizo al amparo de lo dispuesto en el artículo cuarto, apartados b) y d), de la Ley Orgánica 4/1981, de 1 de junio, de los estados de alarma, excepción y sitio (art. 1). La declaración del estado de alarma afectó a todo el territorio nacional (art. 2) y su duración prevista era de quince días naturales (art. 3); todo ello de acuerdo con lo establecido en el texto constitucional ${ }^{2}$.

\footnotetext{
${ }^{1}$ En España solamente se tenía la experiencia de un estado de alarma, hace años, que duró un mes (motivada por la huelga de controladores aéreos).

${ }^{2}$ Artículo 116.2 CE: "El estado de alarma será declarado por el Gobierno mediante decreto acordado en Consejo de Ministros por un plazo máximo de quince días, dando cuenta al Congreso de los Diputados, reunido inmediatamente al efecto y sin cuya autorización no podrá ser prorrogado dicho plazo. El decreto determinará el ámbito territorial a que se extienden los efectos de la declaración”.
} 
Además de contemplarse la posibilidad del dictado de sucesivos estados de alarma (disposición final segunda), se dispuso que el presente Real Decreto entrara en vigor en el momento de su publicación en el Boletín Oficial del Estado (disposición final tercera).

En virtud del citado Real Decreto, se limitó la libertad de circulación de las personas, siendo autorizadas únicamente para hacerlo por las vías de uso público para la realización de determinadas actividades (entre otras: adquisición de alimentos, asistencia a centros sanitarios, desplazamiento al lugar de trabajo, cuidado de mayores y menores...). También, se permitió la circulación de vehículos particulares en esos supuestos (art. 7). Al efecto, se encargó a los agentes de la autoridad la tarea de comprobar si en las personas, bienes, vehículos, locales y establecimientos se llevaban a cabo los servicios y actividades suspendidos ${ }^{3}$.

Por lo que interesa a la Administración de Justicia, destaca principalmente la suspensión de los plazos procesales (regulada en la disposición adicional segunda) ${ }^{4}$, aunque también se suspendieron los plazos administrativos (disposición adicional tercera) ${ }^{5}$; en ambos casos, hasta que terminara el estado de alarma o, en su caso, las sucesivas prórrogas.

En consecuencia, se suspendieron e interrumpieron los plazos previstos en las leyes procesales para todos los órganos jurisdiccionales. Su cómputo se reanudaría en el momento en que perdiera vigencia el Real Decreto o sus posibles prórrogas. No obstante, se contemplaba la posibilidad de que el juez o tribunal pudiera acordar la práctica de actuaciones judiciales necesarias para evitar perjuicios irreparables en los derechos e intereses legítimos de las partes en un proceso.

A tal efecto, se introdujo una distinción entre el orden jurisdiccional penal y los restantes.

Respecto al primero, lógicamente, no sería aplicable en los procedimientos de habeas corpus, actuaciones de los servicios de guardia o con detenido, órdenes de protección, materia penitenciaria y medidas cautelares en materia de violencia sobre la mujer o menores. Además, en la etapa de instrucción, el juez o tribunal competente podría acordar la práctica de actuaciones urgentes.

\footnotetext{
${ }^{3}$ En este sentido, la Orden INT/226/2020, de 15 de marzo (BOE de 15), por la que se establecen criterios de actuación para las Fuerzas y Cuerpos de Seguridad en relación con el Real Decreto 463/2020, de 14 de marzo, por el que se declara el estado de alarma.

${ }^{4}$ Más tarde, el Real Decreto 537/2020, de 22 de mayo (BOE de 23), por el que se aprobó la quinta prórroga del estado de alarma, alzó la suspensión de los plazos procesales, con efectos desde el 4 de junio de ese año (art. 8). También, levantó la suspensión de los plazos de prescripción y caducidad de derechos y acciones (art. 10).

${ }^{5}$ Igualmente, el mismo RD, esta vez con efectos desde el 1 de junio, aprobó la reanudación del cómputo de los plazos administrativos que estuvieran suspendidos (art. 9). Como consecuencia, se derogaron las disposiciones adicionales segunda, tercera y cuarta del RD 463/2000, de 14 de marzo.
} 
En cuanto a los otros órdenes jurisdiccionales, determinados supuestos (procedimiento, autorización judicial o adopción de medidas, según proceda) fueron exceptuados de la mencionada suspensión; así: protección de los derechos fundamentales de la persona y entrada en domicilios u otros lugares (Ley de la Jurisdicción Contencioso-administrativa), conflictos colectivos y tutela de los derechos de los trabajadores (Ley de la jurisdicción social), internamiento no voluntario por trastorno psíquico (Ley de Enjuiciamiento Civil) y protección del menor (Código Civil).

También, durante la vigencia del mencionado Real Decreto y sus eventuales prórrogas, el Pleno del Tribunal Constitucional (Acuerdo de 16 de marzo de 2020, BOE de 17) suspendió los plazos para realizar cualesquiera actuaciones procesales o administrativas ante ese Tribunal. Sin embargo, la suspensión del cómputo de los plazos no afectó a la presentación de recursos y demás escritos, sobre los distintos procesos constitucionales o administrativos, a través del Registro electrónico, ni la declaración del estado de alarma interrumpió el funcionamiento de ese órgano constitucional, que podría continuar dictando las resoluciones y medidas cautelares necesarias en los procesos que lo requiriesen ${ }^{6}$.

\section{LA PREOCUPACIÓN POR LA JUSTICIA (RD-L 16/2020)}

Al mes siguiente, por Real Decreto-ley 16/2020, de 28 de abril (BOE de 29), de medidas procesales y organizativas para hacer frente al COVID-19 en el ámbito de la Administración de Justicia ${ }^{7}$, se procuró atender a los principales problemas surgidos en ese campo debido al estado generalizado de crisis sanitaria.

En su preámbulo, a modo de Exposición de Motivos, se explica que la Administración de Justicia había sufrido una ralentización significativa como consecuencia de la crisis del COVID-19, por lo que se hace necesario aprobar este RD-L que persigue "procurar una salida ágil a la acumulación de los procedimientos suspendidos por la declaración del estado de alarma cuando se produzca el levantamiento de la suspensión". ${ }^{8}$

\footnotetext{
${ }^{6}$ Más tarde, el propio Pleno del Tribunal Constitucional, por Acuerdo de 6 de mayo del mismo año (BOE de 8), decidió que, en todos los procesos constitucionales que ya estuvieran iniciados, los términos y plazos que estaban suspendidos volverían a computarse desde su inicio, siendo por tanto el primer día del cómputo el siguiente hábil a aquél en el que se levantara la suspensión de los procedimientos.

${ }^{7}$ Este RD-L fue convalidado por Acuerdo del Congreso de los Diputados en su sesión de 13 de mayo de 2020 , publicado por Resolución del mismo día (BOE de 15).
}

Fue derogado por la Ley 3/2020, de 18 de septiembre (BOE de 19), de medidas procesales y organizativas para hacer frente al COVID-19 en el ámbito de la Administración de Justicia (disposición derogatoria única).

\footnotetext{
${ }^{8}$ Añadiendo que: “Asimismo, deben adoptarse medidas en previsión del aumento de litigiosidad que se originará como consecuencia de las medidas extraordinarias que se han adoptado y de la propia coyuntura económica derivada de la crisis sanitaria”.
} 
Además, declara que, durante todo el tiempo que perdure la crisis sanitaria, se han de adoptar medidas que garanticen el derecho a la salud de todos los que se relacionan con la Administración de Justicia (personal a su servicio, ciudadanos y profesionales), procurando evitar situaciones de contagio.

El texto se estructuró en tres capítulos, uno claramente procesal, otro referido a materia consursal y societaria, y un tercero sobre aspectos orgánicos y tecnológicos.

\subsection{Capítulo primero}

Destaca la preocupación por el tiempo de las actuaciones procesales, así como se aprueba un nuevo procedimiento especial; de este modo:

\subsection{A. Días hábiles}

Se declaran hábiles para todas las actuaciones judiciales los días 11 a 31 del mes de agosto del 2020, exceptuando los sábados, domingos y festivos, salvo aquellas actuaciones para las que estos días sean ya hábiles ${ }^{9}$ (art. 1). En otras palabras, se habilita de modo excepcional y parcial el mes tradicionalmente considerado vacacional dentro de la actividad judicial. En consecuencia, durante esos días del año 2020, son consideradas urgentes todas las actuaciones procesales.

Se percibe en el legislador una voluntad de recuperar el tiempo para la práctica de diligencias, tras la general suspensión de actividad judicial acordada a mediados del mes de marzo.

A tal efecto, se prescribe que las instituciones afectadas ${ }^{10}$ adoptarán de forma coordinada, en sus respectivos ámbitos, las medidas necesarias para la distribución de las vacaciones de Jueces, Magistrados, miembros del Ministerio Fiscal, Letrados de la Administración de Justicia y demás personal funcionario al servicio de la Administración de Justicia.

A pesar de ese imperativo, el Consejo General del Poder Judicial instó en mayo a los jueces a tomar vacaciones y no fijar juicios en agosto, frente al citado RD-L que habilitaba ese mes (lo que puede entenderse como disconformidad con la intromisión del poder ejecutivo en la independencia judicial). En la práctica dicha disposición resultó, pues, absolutamente inoperativa.

\footnotetext{
${ }^{9}$ Recuérdese que, conforme al artículo 183 de la Ley Orgánica del Poder Judicial, son inhábiles todos los días del mes de agosto, salvo para actuaciones declaradas urgentes.

${ }^{10}$ Consejo General del Poder Judicial, Fiscalía General del Estado, Ministerio de Justicia y Comunidades Autónomas con competencias en materia de Justicia.
} 


\subsection{B. Plazos procesales}

También, se establece que los términos y plazos procesales que quedaron suspendidos por aplicación del Real Decreto 463/2020 (declarando el estado de alarma con motivo del COVID19), volverán a computarse desde su inicio, siendo por tanto el primer día del cómputo el siguiente hábil a aquel en el que deje de tener efecto la suspensión del procedimiento correspondiente. Es decir, como explica el preámbulo del RD-L, no se toma en consideración el plazo (o la parte de éste, añadimos) que hubiera transcurrido previamente a la declaración del estado de alarma.

En cuanto a los plazos para el anuncio, preparación, formalización e interposición de recursos contra sentencias y demás resoluciones que pongan fin al procedimiento y que sean notificadas durante la mencionada suspensión de plazos, así como las que sean notificadas dentro de los veinte días hábiles siguientes al levantamiento de la suspensión de los plazos procesales suspendidos, quedarán ampliados por un plazo igual al previsto en la ley para el anuncio, preparación, formalización o interposición del recurso (artículo 2) ${ }^{11}$.

Obviamente, lo expuesto no será aplicable a los procedimientos cuyos plazos fueron exceptuados de la suspensión.

Hay que valorar positivamente la intención de favorecer el derecho de las partes a la tutela judicial efectiva, facilitando el funcionamiento de los despachos profesionales que vieron afectada su labor durante el tiempo de la pandemia.

Por otra parte, el tiempo de suspensión de actividad judicial, fue aprovechado por jueces y magistrados para dictar el mayor número posible de resoluciones pendientes. Además de los posibles recursos interpuestos contra éstas, era de esperar un importante aumento de otros escritos y demandas, por lo que se persigue la evitación del posible colapso de los tribunales, amén de facilitar a los profesionales la preparación de aquéllos en aras de defender los intereses de sus clientes.

\subsection{Nuevo procedimiento}

Al mismo tiempo, con carácter temporal, se establece un nuevo procedimiento especial y sumario para atender a cuestiones en materia de derecho de familia derivadas de la crisis sanitaria (arts. 3 a 6 ).

\footnotetext{
11 Como prevé el citado preámbulo: “aunque los plazos procesales han sido suspendidos, ..., los jueces y magistrados han venido dictando sentencias y otras resoluciones y se ha continuado con su notificación en la medida en que ha sido posible en función de la reducción de actividad del personal al servicio de la Administración de Justicia. Es previsible, en consecuencia, que en los primeros días en que se retome la actividad judicial ordinaria tras el levantamiento de la suspensión de los plazos procesales, se produzca un notorio incremento en el número de recursos presentados frente a dichas resoluciones".
} 
En efecto, durante la vigencia del estado de alarma (en esos momentos se desconocía su duración definitiva) y hasta tres meses después de su finalización, se decidirán a través del mismo las siguientes materias: a) pretensiones sobre régimen de visitas o custodia compartida que resulten afectadas por las medidas adoptadas por el Gobierno con motivo de la pandemia; b) revisión de medidas sobre cargas del matrimonio, pensiones entre cónyuges y alimentos a los hijos, por haber variado las circunstancias económicas de cónyuges y progenitores; c) establecimiento o revisión de prestar alimentos por cambio en las circunstancias económicas del pariente obligado (art. 3).

En todos los supuestos, el mencionado Real Decreto-ley establece el juzgado competente.

En cuanto a su tramitación, sucintamente los pasos son los siguientes: comienza por demanda de juicio ordinario, acompañada de un principio de prueba documental ${ }^{12}$; tras su admisión por el Letrado de la Administración de Justicia (en su defecto, por el juez), se cita a las partes (y al Ministerio Fiscal, cuando proceda) a una vista. Previamente se intentará que las partes alcancen un acuerdo (si hay un menor, ha de atenderse a su interés superior); también, con carácter previo, puede oírse a los hijos menores (en todo caso, a los mayores de doce años). En la vista serán oídas las partes, pudiéndose solicitar el recibimiento del pleito a prueba ${ }^{13}$, incluso formularse reconvención. Las partes acudirán a la vista con las pruebas de que intenten valerse, practicándose en dicho acto (incluso, las de oficio, en su caso). Después, cabe que formulen oralmente sus conclusiones. El órgano judicial dictará sentencia o auto (según corresponda), de forma oral o por escrito ${ }^{14}$; contra dicha resolución puede interponerse recurso de apelación.

La justificación de este nuevo procedimiento (insistimos en su carácter temporal) se explica por la incidencia que las medidas adoptadas a causa de la epidemia pudieran producir en el régimen de custodia y de visitas de los menores, así como por las consecuencias económicas provocadas por la crisis del COVID-19 y su repercusión en el pago de pensiones alimenticias y en la modificación de medidas.

\footnotetext{
${ }^{12}$ Este consistirá en la aportación del certificado expedido por la entidad gestora de las prestaciones en el que figure la cuantía mensual percibida por ese concepto o por subsidio de desempleo, o bien el certificado de la Agencia Estatal de Administración Tributaria (o, en su caso, de las administraciones tributarias de Navarra o del País Vasco) sobre la declaración de cese de actividad o disminución de ingresos, si son trabajadores por cuenta ajena.

${ }^{13}$ A tal efecto, las partes podrán solicitar, al menos con cinco días de antelación a la fecha de la vista, aquellas pruebas que, habiendo de practicarse en la misma, requieran de citación o requerimiento, o que se soliciten documentos que posean instituciones públicas o privadas.

${ }^{14}$ Si fuera oralmente, se documentará con expresión del fallo y de una sucinta motivación; si todas las partes expresaren su decisión de no recurrir, se declarará en el acto la firmeza de la resolución. En el supuesto de que lo haga por escrito, dispone de un plazo de tres días hábiles para ello y el plazo para recurrir cuenta desde la notificación de la resolución.
} 


\subsection{Tramitación preferente de determinados procedimientos (art. 7 del comentado Real Decreto-ley)}

Hasta el 31 de diciembre de 2020, se tramitarán con preferencia ciertos expedientes y procedimientos.

A saber: a) en materia de jurisdicción voluntaria ${ }^{15}$; b) en el orden jurisdiccional civil ${ }^{16}$; c) en el orden jurisdiccional contencioso-administrativo ${ }^{17}$; y d) en el orden jurisdiccional social ${ }^{18}$.

Como puede apreciarse, aunque pertenecientes a diferentes órdenes jurisdiccionales, se trata de materias que se encuentran en estrecha relación con las medidas adoptadas por el estado de alarma a causa de la epidemia en cuestión. Naturalmente, todo lo regulado se entiende sin perjuicio del carácter preferente que tengan reconocido otros procedimientos de acuerdo con las leyes procesales.

\subsection{Capítulo segundo}

Regula una serie de medidas concursales y societarias con vigencia durante el año siguiente a contar desde la declaración del estado de alarma, que se recogen en los artículos 8 a 18 del presente Real Decreto-ley.

En el preámbulo de esa normativa se reconoce que la ya mencionada crisis sanitaria constituye un obstáculo adicional a la viabilidad de las empresas concursadas, por lo que, a las medidas urgentes acordadas por el Real Decreto-ley 11/2020, de 31 de marzo (que extendió a estas empresas la posibilidad de acceder a un expediente de regulación temporal de empleo conforme al RD-L 8/2020, de 17 de marzo), se añaden ahora otras, con una triple finalidad: a) mantener la continuidad económica de las empresas, profesionales y autónomos que, con anterioridad a la entrada en vigor del estado de alarma, venían cumpliendo regularmente las obligaciones derivadas de un convenio, de un acuerdo extrajudicial de pagos o de un acuerdo de refinanciación homologado; b) potenciar e incentivar la financiación de las empresas para

\footnotetext{
${ }^{15}$ En los que se adopten las medidas a que se refiere el artículo 158 del Código Civil, así como el procedimiento especial y sumario previsto en los artículos 3 a 5 del presente real decreto-ley.

${ }^{16}$ Procesos derivados de la falta de reconocimiento por la entidad acreedora de la moratoria legal en las hipotecas de vivienda habitual y de inmuebles afectos a la actividad económica, los procesos derivados de reclamaciones que pudieran plantear los arrendatarios por falta de aplicación de la moratoria legal o de la prórroga obligatoria del contrato, así como los procedimientos concursales de personas naturales que no sean empresarios.

${ }^{17}$ Recursos contra actos y resoluciones de las Administraciones Públicas por los que se denieguen ayudas y medidas previstas para paliar los efectos económicos producidos por el COVID-19.

18 Tendrán carácter urgente y preferente los procesos por despido o extinción de contrato, los derivados del procedimiento para la recuperación de horas de trabajo no prestadas durante el permiso retribuido (conforme al Real Decreto-ley 10/2020), la aplicación del plan MECUIDA del Real Decreto-ley 8/2020, la impugnación individual, colectiva o de oficio de los expedientes de regulación temporal de empleo por las causas reguladas en este RD-L, así como los que se sustancien para hacer efectivo el trabajo a distancia.
} 
atender sus necesidades transitorias de liquidez; c) evitar el previsible aumento de litigiosidad en relación con la tramitación de concursos de acreedores en los Juzgados de lo Mercantil y de Primera Instancia ${ }^{19}$.

En definitiva -se añade-, se trata de evitar que el escenario posterior al COVID-19 produzca declaraciones de concurso o apertura de la fase de liquidación sobre empresas que podrían ser viables en condiciones generales de mercado, destruyéndose tejido productivo y puestos de trabajo.

Sin embargo, pocos días después, por el Ministerio de la Presidencia, Relaciones con las Cortes y Memoria Democrática, se da a la luz el Real Decreto Legislativo 1/2020, de 5 de mayo (BOE de 7), por el que se aprueba el texto refundido de la Ley Concursal, que entraría en vigor el 1 de septiembre del mismo año.

En su Preámbulo se explica que el Gobierno no sólo aspira a ofrecer un conjunto normativo que fuera sistemático y que fuera claro e inteligible. Por supuesto -añade-, el texto refundido no puede incluir modificaciones de fondo del marco legal refundido, así como tampoco introducir nuevos mandatos jurídicos inexistentes con anterioridad o excluir mandatos jurídicos vigentes.

\subsection{Capítulo tercero}

Contiene una serie de medidas que afectan directamente a la organización de la Administración de Justicia (son las mayoritarias), junto a otra que, aun reconociendo su lógica relación con las anteriores, es más bien de carácter tecnológico.

En general, su duración se extenderá durante la vigencia del estado de alarma (incluidas sus posibles prórrogas) y hasta tres meses después de su finalización (esta extensión durante un plazo tan dilatado hay que valorarlo como un refuerzo de su eficacia). En todo caso, se trata de unas decisiones de carácter temporal tendentes a garantizar la protección de las personas relacionadas con la Administración de Justicia, a la vez que a facilitar su mejor desarrollo.

Sin embargo, por Ley 3/2020, de 18 de septiembre (BOE de 19), de medidas procesales y organizativas para hacer frente al COVID-19 en el ámbito de la Administración de Justicia, se extendieron los plazos de vigencia de estas medidas hasta el 20 de junio de 2021.

\footnotetext{
${ }^{19}$ De este modo, se regulan los siguientes aspectos: modificación del convenio concursal; aplazamiento del deber de solicitar la apertura de la fase de liquidación; acuerdos de refinanciación; régimen especial de la solicitud de declaración del concurso de acreedores; financiaciones y pagos por personas especialmente relacionadas con el deudor; impugnación del inventario y de la lista de acreedores; tramitación preferente; enajenación de la masa activa; aprobación del plan de liquidación; agilización de la tramitación del acuerdo extrajudicial de pagos; y, por último, la suspensión de la causa de disolución por pérdidas.
} 
Respetando en la exposición el mismo orden del comentado RD-L (arts. 19 a 28), son las siguientes:

\subsection{A. Celebración de actos procesales mediante presencia telemática}

Constituido el Juzgado o Tribunal en su sede, todos los actos procesales en general (juicios, comparecencias, declaraciones, vistas y deliberaciones de los tribunales; se incluyen también expresamente los practicados en las fiscalías) se realizarán preferentemente mediante presencia telemática; naturalmente, explicita el texto, siempre que los órganos dispongan de los medios técnicos necesarios (de ahí su carácter preferente, que en ocasiones no será viable).

Como lógica excepción, en el orden jurisdiccional penal será necesaria la presencia física del acusado en los juicios por delito grave.

Por su parte, corrigiendo la anterior redacción, la mencionada Ley 3/2020, de 18 de septiembre, añadió lógicamente que también se requerirá la presencia física del investigado o acusado, a petición propia o de su defensa, en la audiencia prevista en el art. 505 LECRIM cuando cualquiera de las acusaciones interese su prisión provisional o en los juicios cuando alguna de las acusaciones solicite pena de prisión superior a los dos años, salvo que concurran causas justificadas o de fuerza mayor que lo impidan.

Además, cuando se disponga la presencia física del acusado o del investigado, será también necesaria la presencia física de su defensa letrada, a petición de esta o del propio acusado o investigado (art. 14.2, Ley 3/2020).

En cuanto al uso de medios telemáticos, se adoptarán las medidas necesarias para asegurar que se garantizan los derechos de todas las partes en el proceso (especialmente, el derecho de defensa de los acusados e investigados en los procedimientos penales; en particular: el derecho a la asistencia letrada efectiva, a la interpretación y traducción y a la información y acceso a los expedientes judiciales). También, en los actos que se celebren mediante presencia telemática, el juez o Letrado de la Administración de Justicia ante quien se celebren podrá decidir la asistencia presencial a la sede del juzgado o tribunal de los comparecientes que estime necesarios (art. 14.5 y 6 Ley $3 / 2020$ ).

\subsection{B. Acceso a las salas de vistas}

Para garantizar la salud de las personas y atendiendo a las características de las salas de vistas, cada órgano judicial ordenará el acceso del público a todas las actuaciones orales.

Lógicamente, se refiere a las de carácter público y excluidas todas las que se realicen de forma telemática; el juzgado o tribunal ordenará la regulación de su acceso o no, en función de la cabida de la sala y de sus condiciones. Es decir, a pesar de que en términos generales las 
actuaciones judiciales deben gozar de publicidad ${ }^{20}$, por razón de seguridad puede restringirse el acceso a todas las actuaciones (como sucedió en la práctica, incluso en algunas circunscripciones desde un día antes de decretarse el estado de alarma).

Además, ha de respetarse la distancia de seguridad, evitando las usuales aglomeraciones de personas en las sedes judiciales.

\subsection{Exploraciones médico-forenses}

Los informes médico-forenses podrán realizarse basándose únicamente en la documentación médica existente a su disposición, siempre que ello fuere posible (por la abundancia y exhaustividad de aquélla, se entiende).

Se excluye, por tanto, la obligación de exploración directa del herido, incluso del cadáver (lo que podría incluso conducir, en el segundo supuesto, a enterramientos sin previa autopsia).

Una vez más, por insuficiente, la Ley 3/2020, de 18 de septiembre (en sus diversos apartados del art. 16), modificó lo regulado en abril de ese año. En su virtud, además de ampliar el plazo de vigencia de las medidas, dispone que la documentación médica podrá ser requerida a centros sanitarios o a las personas afectadas para que sea remitida por medios telemáticos, siempre que fuere posible. Del mismo modo podrán actuar los equipos psicosociales de menores y familia y las unidades de valoración integral de violencia sobre la mujer.

También, de oficio, o a requerimiento de cualquiera de las partes o del facultativo encargado, el juez podrá acordar que la exploración se realice de forma presencial.

\subsection{Uso de toga}

Se dispensa a las partes que asistan a actuaciones orales del uso de togas en las audiencias públicas. Plazo ampliado hasta el 20 de junio de 2021 (art. 17 Ley 3/2020).

La medida, se entiende que voluntaria y casi de carácter anecdótico, puede explicarse por los abogados que carecen de una toga en propiedad y suelen utilizar las de su corporación profesional. De este modo, se evitan posibles contagios.

\subsection{E. Atención al público}

La atención al público, en cualquier dependencia judicial o de la fiscalía, se realizará por vía telefónica o correo electrónico, siempre que sea posible; obviamente, hay que atender a la protección de datos personales y garantía de los derechos digitales (Ley Orgánica 3/2018, de 5 de diciembre).

\footnotetext{
${ }^{20}$ Constitución Española (art. 120.1) y Ley Orgánica del Poder Judicial (art. 186).
} 
En los supuestos en los que sea imprescindible la presencia física en una sede judicial o del Ministerio Fiscal, hay que obtener previamente una cita. A tal efecto, se establecen unos protocolos que deben contemplar las particularidades de las comparecencias ante los juzgados de guardia y los de violencia sobre la mujer.

Igualmente, se ha ampliado el plazo de vigencia de esta medida hasta el 20 de junio de 2021 (Ley 3/2020, art. 18).

\subsection{F. Órganos judiciales para asuntos de COVID-19}

A la entrada en vigor del presente Real Decreto-ley, existían algunos órganos judiciales pendientes de su puesta en funcionamiento. Pues bien, ahora se contempla la posibilidad de transformarlos en órganos para el conocimiento exclusivo de procedimientos asociados al COVID-19 ${ }^{21}$.

En consecuencia, se habilita al Ministerio de Justicia para que pueda anticipar la entrada en funcionamiento de los órganos judiciales de la programación de 2020, pudiendo dedicarse todos o algunos con carácter exclusivo a conocer de esos procedimientos.

Razones de urgencia, motivadas por la gravedad de la situación, explican el anticipo de su entrada en funcionamiento y la nueva dedicación atribuida.

\subsection{G. Jueces de Adscripción Territorial}

En relación con el anterior apartado, se dispone que los Jueces de adscripción territorial (los llamados JAT), por designación del presidente del Tribunal Superior de Justicia, podrán ejercer sus funciones jurisdiccionales, con carácter preferente, en órganos que conozcan de procedimientos asociados al COVID-19.

\subsection{H. Asignación de funciones}

Durante el mismo tiempo establecido en los anteriores supuestos, los Secretarios Coordinadores Provinciales podrán asignar a los Letrados de la Administración de Justicia y demás funcionarios al servicio de la Administración de Justicia (destinados en las unidades procesales de apoyo directo), la realización de funciones que, siendo propias del Cuerpo al que pertenecen, estén atribuidas a otras unidades; incluso, dicha asignación de funciones podrá realizarse entre el personal destinado en cualquier órgano unipersonal o colegiado.

Se dará preferencia a quienes accedan voluntariamente, sin que ello implique variación de retribuciones. La nueva asignación se hará mediante resolución motivada, fundada en que la

\footnotetext{
${ }^{21}$ De conformidad con la Ley 38/1988, de 28 de diciembre, de Demarcación y de Planta Judicial, el Ministerio de Justicia, previo informe del Consejo General del Poder Judicial y previa audiencia de la Comunidad Autónoma afectada, podrá acordar dicha transformación.
} 
medida resulta imprescindible para garantizar la correcta prestación del servicio, pero solamente se podrá acordar entre unidades u órganos que radiquen en el mismo municipio y que pertenezcan al mismo orden jurisdiccional en que el funcionario venga realizando su actividad.

\subsection{Jornada laboral}

Para los Letrados de la Administración de Justicia y resto del personal, se establecerán jornadas de trabajo de mañana y tarde, para todos los servicios y órganos.

A la par que se atiende a horarios más amplios de apertura, se procura evitar el trabajo en condiciones que no garanticen la distancia social recomendada. Además, permite la celebración de juicios en sesiones de mañana y tarde.

\subsection{J. Sustitución y refuerzo de Letrados de la Administración de Justicia}

Este precepto contempla las enseñanzas prácticas de la formación inicial del Cuerpo de Letrados, que se lleva a cabo en el Centro de Estudios Jurídicos. A tal efecto, se establece que aquéllas podrán realizarse desempeñando labores de sustitución y refuerzo, ejerciendo sus funciones con idéntica amplitud a la de los titulares.

Se regulan otros aspectos (como el informe que se elaborará sobre su rendimiento, colaboración de las Secretarías de Gobierno y percibo de retribuciones), aunque la intención de refuerzo resulta evidente, a la vez que no se interrumpe la formación de los citados profesionales.

\subsection{Otras disposiciones}

Con propio carácter complementario, el comentado Real Decreto contiene las usuales disposiciones adicionales ${ }^{22}$, transitorias $^{23}$, derogatoria ${ }^{24}$ y finales $^{25}$.

\footnotetext{
${ }^{22}$ Se amplían determinados plazos del Registro Civil. Además, por lo que afecta a la jurisdicción militar, la referencia a los Letrados de la Administración de Justicia se entiende extendida a los Secretarios Relatores, a la par que se exceptúa en dicho ámbito la celebración de actos procesales de forma telemática. En cuanto al orden jurisdiccional civil, se suspende temporalmente la aplicación del art. 151.2 LEC respecto a los plazos de comunicación del Ministerio Fiscal.

${ }^{23}$ Regulan el régimen de aplicación temporal del presente Real Decreto-ley a las actuaciones procesales (realizadas a partir de su entrada en vigor), así como previsiones en materia de concurso de acreedores (por presentación de solicitud de concurso necesario, o de apertura de la fase de liquidación o de declaración de incumplimiento).

${ }^{24}$ Se procede a dejar sin vigencia el artículo 43 (plazo del deber de solicitud de concurso) del Real Decreto-ley 8/2020, de 17 de marzo, de medidas urgentes extraordinarias para hacer frente al impacto económico y social del COVID-19.

${ }^{25}$ Dentro de las disposiciones finales, entre otras, se modifica la Ley 18/2011, de 5 de julio, reguladora del uso de las tecnologías de la información y la comunicación en la Administración de Justicia (sobre sistemas de identificación y firma, y la dotación de medios e instrumentos electrónicos y sistemas de información por las Administraciones competentes a todos los órganos, oficinas judiciales y fiscalías), fomentando el teletrabajo, así
} 


\section{LA SITUACIÓN DEL PODER JUDICIAL}

\subsection{Paralización general}

Decretado el estado de alarma a mediados del mes de marzo, con sus consiguientes prórrogas, quedaron prácticamente paralizados los juzgados y tribunales. La excepción se produjo en determinados asuntos penales.

A pesar de la habilitación de los días 11 a 31 de agosto, establecida por el RD-L 16/2020, muchos juristas consideraron ineficaz ese plan de choque del Gobierno. Estimaron que con veinte días más (incluidos varios fines de semana en ellos) no se arreglaba la deficiente situación de la Administración de Justicia, agravada en gran manera por la crisis sanitaria. Lógicamente, ésta también afectó a la incorporación de los funcionarios judiciales a sus puestos de trabajo, que tampoco podían teletrabajar desde sus domicilios debido a la falta de un sistema informático adecuado; es decir, la paralización de la actividad judicial ha sido prácticamente generalizada, a diferencia de otros sectores de la Administración.

En consecuencia, como se difundió en la prensa, desde el propio Consejo General del Poder Judicial se invitó a los jueces a limitar las vistas orales durante esos días ${ }^{26}$.

Obviamente, ello no significó la inactividad total por parte del personal juzgador, que precisamente aprovechó ese tiempo para dictar las numerosas resoluciones pendientes. También, los abogados (como se ha dicho más arriba) pudieron disponer de más tiempo para estudiar los temas encargados, aunque, lógicamente, han sufrido el impacto de la crisis de modo muy directo.

\subsection{Reanudación escalonada}

La actividad judicial comenzó a producirse de forma escalonada. Se establecieron turnos de trabajo y se acondicionaron algunas salas de vistas, especialmente en el orden jurisdiccional penal en que, a pesar de lo dispuesto por el Gobierno, no resultaba válida la celebración de juicios orales por vía telemática y con ausencia de los acusados. Jueces, fiscales y abogados intervinieron detrás de unas mamparas transparentes; también, los acusados y testigos en sus declaraciones27. Los micrófonos se presentaban enfundados con capuchones y se adoptó una

como se prorroga la entrada en vigor de la Ley del Registro Civil (hasta el 30 de abril de 2021), y se dispone la entrada en vigor del propio RD-Ley (al día siguiente de su publicación en el BOE).

${ }^{26}$ A título de ejemplo, todos los Juzgados de lo Penal de la provincia de Sevilla decidieron no celebrar juicios a lo largo del mes de agosto. El CGPJ les había recordado que la decisión de celebrarlos o no correspondía al titular de cada órgano judicial. En nuestra opinión, una falta de sintonía más entre el órgano de gobierno de los jueces y el poder ejecutivo que, al parecer, actuó sin contar previamente con los primeros.

${ }^{27}$ Sin embargo, a principios del mes de junio, en la provincia de Granada fue suspendida la celebración del primer juicio con jurado popular desde la crisis sanitaria. Aunque la sala se había acondicionado con mamparas, el total 
serie de medidas preventivas (lavado de manos, uso de geles alcohólicos y de mascarillas, dispensa de la obligación de portar toga, distancia social, desinfección de salas, etcétera).

\subsection{Nuevos órganos judiciales}

Los órganos judiciales anunciados por el Ministerio de Justicia en abril de 2019 y cuya entrada en vigor estaba prevista para marzo de 2020 no comenzarían a actuar hasta el mes de septiembre, debido a la epidemia. La casi absoluta paralización de la Administración de Justicia ha repercutido también en ello.

\subsection{Cursos de especialización y oposiciones a la Carrera Judicial y Fiscal}

Conforme se fue paulatinamente normalizando la situación sanitaria, las instituciones comenzaron a recobrar su anterior ritmo de funcionamiento.

En este sentido, por Acuerdos de 27 de mayo y de 4 de junio de 2020 (publicados en el BOE de 8 de junio), de la Comisión Permanente del Consejo General del Poder Judicial, se convocaron pruebas de especialización para la provisión de plazas de Magistrado especialista en los órdenes jurisdiccionales social y contencioso-administrativo, así como pruebas de promoción y especialización en los asuntos propios de los órganos de lo mercantil ${ }^{28}$.

Por lo que se refiere a las oposiciones para ingreso en la Carrera Judicial y en la Carrera Fiscal, por Acuerdo de 25 de marzo de 2020 (BOE de 27), el Consejo General del Poder Judicial, a través de la Comisión de Selección, debido a la situación del estado de alarma declarado con motivo de la crisis sanitaria ocasionada por el COVID-19, acordó la suspensión temporal del proceso selectivo en curso para la provisión de plazas de alumnos de la Escuela Judicial, para su posterior ingreso a la Carrera Judicial por la categoría de Juez, y plazas de alumnos del Centro de Estudios Jurídicos, para su posterior ingreso en la Carrera Fiscal por la categoría de Abogado Fiscal.

Más tarde, la mencionada Comisión, con fecha de 10 de junio de 2020 (BOE de 13), ante el cese el día 21 de junio de la situación de estado de alarma, acordó reanudar el mencionado proceso selectivo ${ }^{29}$.

previsible de asistentes (fiscal, acusaciones, defensa, jurados titulares y suplentes, tribunal, técnico de auxilio judicial y acusado), en una sala sin ventilación, aconsejó la decisión.

${ }^{28}$ Para acceder a las pruebas, entre otros requisitos exigidos a las personas aspirantes, será preciso acreditar "haber participado en actividades de formación continua con perspectiva de género con un mínimo de cincuenta horas lectivas" (Base segunda. 4).

${ }^{29}$ Que había sido aprobado el año anterior (concretamente por Acuerdo de 5 de julio de 2019, BOE de 8) y posteriormente suspendido, como hemos apuntado (por Acuerdo de 25 de marzo de 2020, BOE de 27). 


\section{EL MINISTERIO DE JUSTICIA}

Algunas medidas acordadas en su seno se justificaban por la grave situación sanitaria producida; por el contrario, estimamos que otras podían haber esperado unas circunstancias más adecuadas.

Entre las primeras, cabe citar la Orden JUS/332/2020, de 6 de abril (BOE de 9), por la que se concede una subvención directa al Consejo General de Procuradores de España en materia de prestación de asistencia jurídica gratuita, para el ejercicio presupuestario de ese año.

También, por Orden JUS/394/2020, de 8 de mayo (BOE de 9), se aprobó el Esquema de Seguridad Laboral y el Plan de Desescalada para la Administración de Justicia ante el COVID$19^{30}$.

En la misma línea, por Resolución de 11 de mayo de 2020 (BOE de 13), de la Dirección General para el Servicio Público de Justicia, se procede al alzamiento de la suspensión de la realización de la prueba de aptitud profesional para el ejercicio de la profesión de Abogado y se acuerda la convocatoria de la prueba ${ }^{31}$. Más adelante, por Orden PCM/467/2020, de 29 de mayo (BOE de 30), del Ministerio de la Presidencia, Relaciones con las Cortes y Memoria Democrática, se modificó la Orden por la que se convocaba la mencionada prueba de evaluación, pues las actuales circunstancias desaconsejaban su realización de forma presencial ${ }^{32}$.

Sin embargo, como hemos apuntado, tal vez la urgencia no justificara algunas decisiones, que posiblemente hubieran requerido en su lugar dedicar los esfuerzos a un mejor funcionamiento de la Administración de Justicia, gravemente afectada por la declaración del estado de alarma. En este sentido, nos referimos a la tramitación de los indultos y a la Comisión para la elaboración del anteproyecto de una nueva Ley de Enjuiciamiento Criminal.

En cuanto a la primera, por Resolución de 20 de marzo de 2020 (BOE de 21), de la Subsecretaría del Ministerio de Justicia, se acuerda reanudar por razones de interés general todos los procedimientos para solicitar y conceder la Gracia de Indulto que estuvieran en tramitación con

\footnotetext{
${ }^{30}$ Activando la Fase I del Plan con efectos desde el 12 de mayo y aprobando los criterios para la asistencia en turnos de tarde. Por cierto, en el Anexo II se recogen las cuatro fases de incorporación presencial del personal incluido en dicha Orden.

${ }^{31}$ Por Orden PCI/1261/2019, de 26 de diciembre, se había convocado la correspondiente prueba de evaluación de aptitud profesional. Con fecha 6 de marzo de 2020 el Ministerio de Sanidad recomendó su aplazamiento en atención a la incidencia que estaba teniendo el contagio del coronavirus. A la vista de ello, por Resolución de 10 de marzo, se acordó suspender la celebración de la mencionada prueba.

${ }^{32}$ En consecuencia, para el año 2020, pasa de ser escrita y presencial a celebrarse on line de manera síncrona a través de la plataforma AVEX de la Universidad Nacional de Educación a Distancia.
} 
fecha 14 de marzo de 2020 o que se hubieran iniciado o fueran a iniciarse con posterioridad ${ }^{33}$. Lo mismo se produjo en el Ministerio de Defensa, por Resolución 400/38088/2020, de 23 de marzo, de la Subsecretaría (BOE de 24).

Por lo que respecta a la Comisión de Expertos, en plena crisis sanitaria producida por la pandemia, a principios del mes de mayo el Ministerio de Justicia dio a conocer su constitución para la elaboración del anteproyecto de Ley de Enjuiciamiento Criminal (LECrim).

Cinco fiscales, tres magistrados y dos profesores de Derecho Procesal integran el grupo de expertos, coordinado por el magistrado de la Audiencia Provincial de Madrid Juan José López Ortega, quien presidirá la comisión. Cinco de sus miembros, incluido el coordinador, participaron en 2011 en la elaboración de la correspondiente propuesta de reforma normativa del anterior Gobierno socialista.

El Ministro de Justicia la ha incluido entre las prioridades de su mandato, comprometiéndose a presentar un texto para su aprobación por el Consejo de Ministros antes del final de 2020.

\section{LA FISCALÍA GENERAL DEL ESTADO Y LOS PLAZOS DE INSTRUCCIÓN}

La tradicional redacción de nuestro texto procesal penal establecía que el sumario debía terminarse en el plazo de un mes, lo que evidentemente resultaba de imposible cumplimiento, sobre todo en las causas de cierta complejidad. Aunque tardíamente, la Ley 41/2015, de 5 de octubre (BOE de 6), de modificación de la Ley de Enjuiciamiento Criminal para la agilización de la justicia penal y el fortalecimiento de las garantías procesales, reformó de modo importante dicha situación ${ }^{34}$.

Sin embargo, el tema adquirió especial relevancia durante la comentada pandemia. Sabido es que, a causa de la crisis sanitaria, el Gobierno paralizó la actividad judicial no esencial (remitimos a lo expuesto más arriba). Pues bien, la Fiscalía General del Estado (presidida por la anterior Ministra de Justicia, Dolores Delgado), planteó la posibilidad de poner el reloj a cero

\footnotetext{
${ }^{33}$ En la presentación de la Resolución, el Poder ejecutivo explica que "el interés general que concurre en estos supuestos es el mismo que constituye el fundamento de su excepcionalidad, la consecución de la justicia material".

${ }^{34}$ En síntesis, la regulación de 2015 quedó del siguiente modo (art. 324 LECRIM): como principio general, las diligencias de instrucción se practicarían durante el plazo máximo de seis meses desde la fecha del auto de incoación del sumario o de las diligencias previas. Es lo que se calificó como instrucción sencilla o normal. Antes de la expiración de ese plazo, el instructor, a instancia del fiscal y previa audiencia de las partes, podía declarar la instrucción compleja, porque la primera no pudiera razonablemente terminarse dentro de los seis meses. El plazo de duración de la instrucción compleja sería de dieciocho meses, que el instructor podía prorrogar por igual plazo o uno inferior (con lo que la instrucción podía elevarse hasta tres años de duración), igualmente a instancia escrita del fiscal y oídas las partes restantes. Se contemplaba, también, la posibilidad excepcional de que, antes de que transcurrieran los plazos establecidos para la instrucción sencilla o para la compleja o, en su caso, el de la prórroga, el instructor pudiera fijar un nuevo plazo máximo para la finalización de la instrucción, previa audiencia de las partes.
} 
en los plazos de instrucción, en lugar de reanudarlos desde que se interrumpieron. En este sentido, propuso la posibilidad de que los plazos comenzaran a computarse no solo para presentar un recurso, sino para todas las investigaciones penales que habían quedado suspendidas y cuyos límites temporales estaban bien definidos en la anteriormente citada reforma de octubre de 2015. Se habló, incluso, de derogar los plazos establecidos para la instrucción, lo que exigiría otra reforma legal. Ello supondría practicar instrucciones penales sin plazos máximos. Ni que decir tiene que, de haber prosperado dicha opinión, importantes sumarios llevados a cabo en juzgados de Sevilla habrían recibido un aplazamiento sine die.

Esta opinión de la Fiscal General recibió críticas por parte de un sector ${ }^{35}$. De un modo más extenso y contundente, GONZÁLEZ-CUÉLLAR SERRANO manifestó que en tiempo de coronavirus una derogación de los plazos de instrucción tenía "el inequívoco significado objetivo de una autoamnistía encubierta", mediante la colocación del "manto del olvido" sobre las legítimas reclamaciones que ya se estaban planteando. Asimismo, calificó de sarcástica la actitud de la Fiscalía Anticorrupción que, en una nota de prensa, invocó la bondad de una derogación fáctica de los plazos de instrucción por su pretendida utilidad para el ejercicio de un hipotético derecho de los investigados a demostrar su inocencia ${ }^{36}$.

Afortunadamente, la situación no llegó a mayores y al poco tiempo se aprobó por la Comisión de Justicia del Congreso de los Diputados una Proposición de Ley (BOCG, entrada en el Senado el 1 de julio de 2020), convertida posteriormente en Ley 2/2020, de 27 de julio, por la que se modifica el artículo 324 de la Ley de Enjuiciamiento Criminal (BOE, de 28 de julio). En su Preámbulo se explica que: "Si bien establecer sin más un límite máximo a la duración de la instrucción se ha evidenciado pernicioso por cuanto puede conducir a la impunidad de la persecución de delitos complejos, no es menos cierto que establecer ciertos límites a la duración de la instrucción supone una garantía para el derecho de los justiciables" ${ }^{\text {37. }}$.

${ }^{35}$ Entre otros, algunos letrados en el conocido caso de los ERE en Andalucía manifestaron su sensata preocupación
al respecto, como: Adolfo CUÉLLAR PORTERO, que expresó que los únicos plazos que debían reiniciarse son
los que afectaran a los recursos o a la presentación de escritos de calificación, no a los establecidos en el artículo
324 de la Ley de Enjuiciamiento Criminal, y Manuel PÉREZ CUAJARES, para quién no cabe la confusión de un
plazo concedido a las partes para que no se vea perjudicada la tutela judicial efectiva, con los plazos de instrucción
(Diario ABC de Sevilla, de 1 de junio de 2020).
36 Añadiendo que: "Con suerte para el poder, sin plazos, los juicios se celebrarán en quince o veinte años, donde
la verdad es más fácilmente manipulable, donde podrá haberse silenciado o -peor aún- convertido en mito, gracias
a la propaganda" (El tiempo y el Derecho: el artículo 324 de la Ley de Enjuiciamiento Criminal, en
CONFILEGAL, 7 de mayo de 2020 ). En otro lugar, el mismo autor afirma: "sólo desde el más puro tancredismo
del alma española puede entenderse la extendida opinión en la carrera judicial y fiscal contraria a los plazos de la
instrucción establecidos por el art. 324 de la Ley de Enjuiciamiento Criminal tras su reforma en 2015, aprovechada
oportunistamente desde la política para sus peculiares ajustes de cuentas y maniobras de distracción de la opinión
pública mediante la ceremonia de la confusión" (La inacción procesal o la estatua de Don Tancredo, en El Español,
11 de mayo de 2020).
37 La nueva redacción del art. 324 LECRIM queda, pues, del siguiente modo: la investigación judicial se
desarrollará en un plazo máximo de doce meses desde la incoación de la causa. Si, con anterioridad a la fínalización
del plazo, se constatare que no será posible finalizar la investigación, el juez, de oficio o a instancia de parte, oídas 


\section{LOS COLEGIOS DE ABOGADOS}

Sin duda, la pandemia, con el consiguiente confinamiento, influyó decisivamente en la actividad de los despachos de abogados. Aunque reseñaremos el de Sevilla, muy representativo dentro del ámbito andaluz por el elevado número de sus colegiados, el comentario puede extenderse a todas las corporaciones profesionales españolas de esta clase.

De este modo, hubo provincias en las que en las primeras semanas de junio se produjo alguna que otra concentración de abogados, procuradores y graduados sociales, ante la Audiencia Provincial. Como señal de protesta, en la primera de las celebradas en la ciudad de Sevilla se lanzaron togas al cielo.

Exigían la reactivación de la Administración de Justicia, para volver a la normalidad (sin tener que esperar al 15 de septiembre) y poder acceder libremente a los juzgados (hasta ahora la entrada está limitada a ciertos trámites y con cita previa). Hablaban de una parálisis total en la Justicia. Como muestra demostrativa de la realidad, baste decir que en dicha ciudad se están señalando vistas para 2023 y 2024.

Por otra parte, ante la situación que la epidemia ha producido en la actividad profesional de los letrados, con el consiguiente descenso de ingresos económicos en los despachos, el Colegio de Abogados de la mencionada ciudad acordó el adelanto del 50 por ciento del pago del segundo trimestre de guardias y oficios. Con ello se pretendía paliar en la medida de lo posible la grave situación de muchos colegiados que han intervenido en el turno de oficio.

También resulta de interés la Orden SND/261/2020, de 19 de marzo (BOE de 20), para la coordinación de la actividad profesional de los miembros de los cuerpos de funcionarios regulados en el libro VI de la Ley Orgánica del Poder Judicial, durante el estado de alarma. Pues bien, en ella se encomienda al Ministro de Justicia, además de la citada coordinación, la de los servicios públicos prestados a través de los Colegios Profesionales que actúan en el ámbito de la Administración de Justicia y, en particular, el turno de oficio y la asistencia jurídica gratuita (apartado primero).

Igualmente, hemos de mencionar la Resolución de 16 de abril de 2020 (BOE de 28), del Ministerio de Política Territorial y Función Pública, por la que se publicó el Convenio, suscrito en Madrid el 15 de abril, entre la Administración General del Estado (perteneciente al citado

las partes podrá acordar prórrogas sucesivas por períodos iguales o inferiores a seis meses. El juez concluirá la instrucción cuando entienda que ha cumplido su finalidad. 
Ministerio) y el Consejo General de la Abogacía Española, en relación con la realización de trámites administrativos y gestión documental por vía electrónica ${ }^{38}$.

\section{EL ESTADO DE ALARMA ENTRE REJAS}

La pandemia ha afectado a los recluidos en los centros de internamiento, incluidos los de menores; especialmente, se ha percibido en los de extranjeros ${ }^{39}$.

Sin embargo, en el sistema penitenciario se actuó con mayor previsión. En este sentido, la Orden INT/227/2020, de 15 de marzo (BOE del mismo día), en relación con las medidas que se adoptan en el ámbito de Instituciones Penitenciarias al amparo del Real Decreto 463/2020, de 14 de marzo, por el que se declara el estado de alarma, dispuso que, durante la vigencia del estado de alarma: a) se suspendían todas las comunicaciones ordinarias de los internos en los centros penitenciarios; b) y salidas de todo tipo, salvo casos de fuerza mayor o necesidad e internos que se encontraran en tercer grado, secciones abiertas, etcétera.

Para paliar los efectos nocivos del aislamiento, se ordenó la ampliación de las comunicaciones telefónicas autorizadas, especialmente con sus abogados, a fin de que en todo momento quedara garantizado el derecho de defensa.

Más tarde, se suavizaron esas medidas. De este modo, por Orden INT/407/2020, de 12 de mayo (BOE de 13), además de derogar la anterior Orden INT 227/2020, se adoptaron medidas para flexibilizar las restricciones establecidas en el ámbito penitenciario, explicado por el inicio de un proceso de reducción gradual de las medidas extraordinarias de restricción de la movilidad.

En consecuencia, se perseguía reanudar en los centros penitenciarios, de forma paulatina y gradual, las siguientes actividades: a) comunicaciones ordinarias de los internos; b) salidas de permiso y programadas; c) salidas de los internos clasificados en tercer grado o que tengan aplicado el régimen de flexibilidad y se hallen destinados en centros de inserción social, secciones abiertas o centros ordinarios; d) traslados de internos cuando sean solicitados por las autoridades judiciales, traslados por razones humanitarias u otros que lo requieran por indicaciones sanitarias; y e) actividades educativas, formativas, terapéuticas, deportivas, culturales y religiosas en el interior de los centros penitenciarios, en función de la situación de estos y de las medidas que se pudieran adoptar por las autoridades competentes.

\footnotetext{
${ }^{38}$ Dicho Convenio persigue hacer posible que la presentación electrónica de documentos en representación de los ciudadanos por parte de los abogados se beneficie del régimen especial que establece la Ley 39/2015, de 1 de octubre, del Procedimiento Administrativo Común de las Administraciones Públicas (concretamente, el art. 5.7).

${ }^{39}$ A título de ejemplo, según la prensa, el Centro de Estancia Temporal de Emigrantes (CETI) de Melilla (con 782 plazas de capacidad, albergaba en agosto a 1.354 personas; 43 en aislamiento por haberse detectados como positivos) se encontraba saturado. Una situación de hacinamiento que, irremediablemente, derivó en un grave motín a finales de ese mes.
} 


\section{LAS PRÓRROGAS DEL ESTADO DE ALARMA}

\subsection{Hasta junio de 2020}

Como se ha expuesto más arriba, el Gobierno, en reunión extraordinaria del Consejo de Ministros de 14 de marzo de 2020, aprobó el Real Decreto 463/2020, de 14 de marzo, por el que declaró el estado de alarma para la gestión de la situación de crisis sanitaria ocasionada por el COVID-19. Se dispuso que su entrada en vigor fuera en el momento de su publicación en el Boletín Oficial del Estado (disposición final tercera), lo que se produjo el mismo día.

Pues bien, conforme a lo dispuesto en la LO 4/1981, de 1 de junio, de los estados de alarma, excepción y sitio, se estableció que la duración de dicho estado sería de quince días naturales (artículo $6^{\circ} .2$ ), contemplándose además la posibilidad de prórroga del estado de alarma (disposición final segunda).

En tal sentido, se produjeron varias (todas acordadas en Consejo de Ministros y posteriormente autorizadas por el Congreso de los Diputados).

La primera fue por Real Decreto 476/2020, de 27 de marzo (BOE de 28) y la prórroga se extendió hasta las 00:00 horas del día 12 de abril ${ }^{40}$. La segunda se produjo por Real Decreto 487/2020, de 10 de abril (BOE de 11), extendiéndose hasta las 00:00 horas del 26 de abril ${ }^{41}$. La siguiente prórroga del estado de alarma tuvo lugar por Real Decreto 492/2020, de 24 de abril (BOE de 25), y se extendió hasta las 00:00 horas del día 10 de mayo ${ }^{42}$. La cuarta (Real Decreto 514/2020, de 8 de mayo, BOE de 9) se extendió hasta las 00:00 horas del día 24 de mayo ${ }^{43}$. La siguiente prórroga fue aprobada por Real Decreto 537/2020, de 22 de mayo (BOE de 23), extendiéndose hasta las 00:00 horas del día 7 de junio ${ }^{44}$. Finalmente, por Real Decreto

\footnotetext{
${ }^{40}$ El correspondiente Acuerdo del Consejo de Ministros fue de 24 de marzo y la autorización requerida fue concedida por el Pleno del Congreso de los Diputados en su sesión de 25 de marzo (BOE de 28). El Gobierno explicó que, a la luz de los datos e informes disponibles, no se puede afirmar que la situación de emergencia sanitaria se habrá superado completamente en el plazo previsto inicialmente, "por lo que se estima imprescindible prorrogar el estado de alarma", con el fin de "garantizar la eficaz gestión de la emergencia sanitaria y contener la propagación de la enfermedad".

${ }^{41}$ El Acuerdo del Consejo de Ministros se adoptó el 7 de abril y el Pleno del Congreso de los Diputados, en su sesión de 9 de abril (BOE de 11), concedió la autorización solicitada. El Gobierno argumentó "la experiencia comparada en la aplicación de medidas similares adoptadas en Estados en los que se ha producido una incidencia intensa y más temprana de la pandemia".

${ }^{42}$ Esta tercera prórroga fue acordada por Consejo de Ministros el 21 de abril, concediéndose su autorización por el Congreso de los Diputados el día 22 de abril (BOE de 25). Se concluyó que los beneficios derivados de la nueva prórroga eran mayores que los perjuicios ocasionados.

${ }^{43}$ El Acuerdo del Consejo de Ministros se produjo el 5 de mayo y la autorización del Congreso de los Diputados fue el 6 (BOE de 9). Igualmente, "se estima imprescindible prorrogar de nuevo el estado de alarma".
}

${ }^{44}$ El Consejo de Ministros la aprobó el 19 de mayo y el Congreso de los Diputados el 20 (BOE de 23). 
$555 / 2020$, de 5 de junio (BOE de 6), se declara prorrogado el estado de alarma, por sexta y última vez, hasta las 00:00 horas del día 21 del mismo mes de $2020^{45}$.

\subsection{Por plazo superior}

A mediados de mayo se planteó por parte del Gobierno la posibilidad de solicitar en el Congreso de los Diputados la votación favorable para la prórroga de un mes del estado de alarma, en vez de los quince días como se había hecho hasta el momento.

En nuestra opinión, ello hubiera constituido un fraude de derecho. La ley habla de un plazo de quince días ${ }^{46}$, prorrogable, y eso significa -en su caso- renovar la autorización de ese plazo, incluso reducirlo. Ampliarlo no sería prorrogar el plazo, sino modificarlo o alterarlo. Así se refieren los textos legales a los numerosos supuestos en los que se contempla la posibilidad de ampliar un plazo.

¿Por qué un mes y no tres o seis, incluso una prórroga por un año? Lógicamente, tal pretensión no prosperó y las solicitudes de prórroga del estado de alarma que se plantearon al Congreso de los Diputados fueron siempre por quince días.

\subsection{Los estados de alarma en el futuro}

Por otra parte, redactando estas notas sobre la repercusión de la pandemia y del estado de alarma en nuestra Administración de Justicia, se difunde la noticia de la posibilidad de que el Gobierno deje en manos de las Comunidades Autónomas la solicitud -y su correspondiente defensa parlamentaria- del estado de alarma en cada territorio.

De este modo, se abriría la puerta a que, en un determinado momento, convivan simultáneamente en España diversos estados de alarma; por supuesto, con diversos ámbitos territoriales y duración temporal. En todo caso, las prórrogas deberían ser refrendadas por el Parlamento.

Como fundamento legal, se esgrime el art. 116.2 CE y el Ley Orgánica de los estados de alarma, excepción y sitio.

En efecto, dichos preceptos contemplan dicha posibilidad, aunque consideramos que el estado de alarma está concebido para una situación concreta (p. e. un incendio de grandes proporciones

\footnotetext{
${ }^{45}$ El Acuerdo del Consejo de Ministros tuvo lugar el 2 de junio y la aprobación del Congreso de los Diputados fue el día 3 (BOE de 6) del mismo mes y año.

${ }^{46}$ Artículo 116.2 CE: "El estado de alarma será declarado por el Gobierno mediante decreto acordado en Consejo de Ministros por un plazo máximo de quince días, dando cuenta al Congreso de los Diputados, reunido inmediatamente al efecto y sin cuya autorización no podrá ser prorrogado dicho plazo. El decreto determinará el ámbito territorial a que se extienden los efectos de la declaración”.
} 
o un terremoto) pero no generalizada de peligro (p. e. la pandemia). Habría que someter al Congreso la aprobación de numerosas situaciones particulares.

Tampoco falta quien opina que es suficiente con la Ley Orgánica 3/1986, de Medidas Especiales en Materia de Salud Pública, la Ley de Seguridad Nacional o la Ley del Sistema de Protección Civil.

Por último, hay que mencionar que, unos meses después de la declaración del estado de alarma, se han adoptado confinamientos perimetrales de determinadas ciudades; así, en Madrid, decretado por el Gobierno Central, o en ciudades más pequeñas (como Écija y Casariche, en la provincia de Sevilla, acordados por el Gobierno autonómico).

\section{RECURSOS DE INCONSTITUCIONALIDAD}

Por providencias de 6 de mayo de 2020 (BOE de 8), el Pleno del Tribunal Constitucional acordó admitir a trámite el recurso de inconstitucionalidad número 1813-2020, promovido por más de cincuenta diputados del Grupo Parlamentario de VOX en el Congreso, así como el recurso de inconstitucionalidad número 2035-2020, promovido por más de cincuenta senadores del Grupo Parlamentario Popular del Senado, ambos contra la disposición final segunda del Real Decretoley 8/2020, de 17 de marzo, de medidas urgentes extraordinarias para hacer frente al impacto económico y social del COVID-19 ${ }^{47}$.

Además, por otra providencia de ese día, el TC acordó admitir a trámite distinto recurso de inconstitucionalidad (el número 2054-2020), del mencionado Grupo VOX, en relación con los arts. 7, 9, 10 y 11 del Real Decreto 463/2020, de 14 de marzo, por el que se declara el estado de alarma para la gestión de la situación de crisis ocasionada por el COVID-19; Real Decreto 465/2020, de 17 de marzo, en cuanto modifica el art. 7 del Real Decreto 463/2020; Reales Decretos 476/2020, de 27 de marzo, 487/2020, de 10 de abril y 492/2020, de 24 de abril, en cuanto aprueban sucesivas prórrogas del estado de alarma; Real Decreto 492/2020, además, en cuanto da nueva redacción al art. 7 del Real Decreto 463/2020; y Orden SND/298/2020, de 29 de marzo, por la que se establecen medidas excepcionales en relación con los velatorios y ceremonias fúnebres para limitar la propagación y el contagio por el COVID-19. Estos recursos no han sido resueltos todavía.

\footnotetext{
${ }^{47}$ La mencionada disposición final modifica la Ley 11/2002, de 6 de mayo, reguladora del Centro Nacional de Inteligencia. En concreto, reformó el apartado 2 de su artículo 6, sobre la composición de la Comisión en la que se integran, entre otros, a los vicepresidentes del Gobierno, incluido el vicepresidente cuarto (del Grupo Unidas Podemos). Una deficiente técnica legislativa, conocida como de decreto ómnibus, utilizada para incorporar en un texto legal una reforma que nada tiene que ver con la normativa anunciada.
} 


\section{CONCLUSIONES}

En términos generales, durante el primer estado de alarma (con sus prórrogas) se ha producido una paralización de la Administración de Justicia, con previsibles consecuencias en orden a una sustancial acumulación de asuntos judiciales una vez que se levantara aquél.

Algunas de las medidas adoptadas han tenido un mero carácter testimonial, cuando no una manifiesta inutilidad.

Otras disposiciones se han dictado con una deficiente técnica legislativa; así, en los decretos leyes se contemplan aspectos muy concretos, cuya regulación debería haberse hecho en órdenes ministeriales.

Además, como hemos dicho, se ha aprovechado el estado de alarma para aprobar disposiciones que nada tienen que ver con la pandemia.

Especial mención merece la citada Ley 3/2020, de 18 de septiembre (BOE de 19), de medidas procesales y organizativas para hacer frente al COVID-19. En ella, además de derogar el Real Decreto-ley 16/2020, en síntesis, sigue la línea de esa norma, aunque con la introducción de algunas modificaciones a las que puntualmente hemos hecho referencia más arriba.

\section{2. ÚLTIMA HORA}

Terminado este trabajo, el Gobierno, en reunión extraordinaria del Consejo de Ministros, ha aprobado un nuevo estado de alarma, que finalizará a las 00:00 horas del día 9 de noviembre del presente año, sin perjuicio de las prórrogas que puedan aprobarse más adelante.

En efecto, por Real Decreto 926/2020, de 25 de octubre (BOE de 25), se declara el estado de alarma para contener la propagación de infecciones causadas por el SARSCOV-2.

Su entrada en vigor ha sido el mismo día de su publicación en el Boletín Oficial del Estado (disposición final segunda del RD).

Además, en la actualidad se debate la propuesta del Gobierno de extender su vigencia durante seis meses. Esa posibilidad, con efectos que llegarían hasta el mes de mayo de 2021, está siendo criticada por numerosos juristas y fuerzas políticas.

A todo ello, es igualmente de aplicación lo expuesto en las páginas de arriba, aunque han sido redactadas teniendo en cuenta el estado de alarma declarado en el mes de marzo de este año. 